\title{
An Investigation into News Webpage interface Design in Kurdistan Region of Iraq
}

\author{
Hoger Mahmud Hussen \\ University of Human \\ Development \\ Department of Computer Science \\ hoger.mahmud@uhd.edu.iq
}

\author{
Mazen Ismaeel Ghareb \\ University of Human \\ Development \\ Department of Computer Science \\ mazen.ismaeel@uhd.edu.iq
}

\author{
Zana Azeez Kaka Rash \\ University of Human \\ Development \\ Department of Computer Science \\ zana.aziz@uhd.edu.iq
}

\begin{abstract}
Recently the Kurdistan Region of Iraq has experienced an explosion in exposure to new technologies in different sectors especially in media and telecommunication. Internet is one of those technologies that have opened a way for information proliferation amongst a previously censored region.

Developing web sites to deliver news and other information is a relatively new phenomenon in Kurdistan; this means that the design and development of web pages may lack the quality standard required. In this paper the quality of webpage interface design and usability in the field of news journalism in the KRI is examined against a set of web interface design and usability criterion. For the purpose of data collection 9 available popular news websites are chosen and 900 questionnaires are sent to 100 random users. The result is analyzed and we have found that the majority of users are satisfied with the interface design and usability of the news WebPages, however the result points out some weakness that can be improved. The outcome of this research can be used to enhance website design and usability in the field of journalism in the KRI.
\end{abstract}

Keywords-KRI (Kurddistan Region of Iraq); HCI (Human Computer Interface)

\section{INTRODUCTION}

Recently the Kurdistan Region of Iraq has experienced an explosion in exposure to new technologies in different sectors especially in media and telecommunication. Internet is one of those technologies that have opened a way for information proliferation amongst a previously censored region.[1] as researched the state of internet availability and issues related to that in the KIR. Developing web sites to deliver news and other information is a relatively new phenomenon in Kurdistan; this means that the design and development of WebPages may lack the quality standard required. In this paper the quality of webpage interface design and usability in the field of news journalism in the KRI is examined against a set of web interface design and usability criteria.

The non English-speaking users are growing rapidly with expansion of internet and World Wide Web, For instance Chinese speaking users has grown up to $1087.7 \%$ [2]. Kurdish language is the second official language in Iraq and there are growing numbers of Kurdish websites.
Therefore, it is important to study and evaluate the quality of the interface designs of the websites to improve and increase user satisfaction.

For the purpose of data collection 9 available popular news websites are chosen and in total 900 questionnaires are sent to 100 random users. We have found that the majority of users are satisfied with the interface design and usability of the news WebPages, however the result points out some weaknesses that can future designs. The outcome of this research can be used to enhance website design and usability in the field of journalism in the KRI.

\section{BACKGROUND RESEARCH}

In this section we provide some background information

\section{A. Human Computer Interface (HCI)}

HCI has been getting increasing attention by researchers as the relationship between man and machine is becoming ever more essential to the way of life. HCI is described by [3] as "a discipline concerned with the design, evaluation and implementation of interactive computing systems for human use and with the study of major phenomena surrounding them"

It is clear that a machine is deemed useless unless it can be used by men, this basic concept should be considered in the design of $\mathrm{HCI}$ in terms of functionality and usability. One other factor that should be considered is the degree of activity that brings both user and machine together. [4] Suggests three different levels of user activity which are physical, cognitive and affective. The physical level deals with the mechanics of interaction and the cognitive level deals with "ways user can understand and interact with the system".

\section{B. Web Usability}

Usability in general is an essential aspect of systems that can determine the success or failure of a system, [5] describes usability as "the ability to find one's way around the Web, to locate desired information, to know what to do next and, very importantly, to do so with minimal effort". The idea of usability in terms of functionality in a system can be summarized in system navigation and search. 
The concept of navigation in a web based context is more commonly known as "browsing" and it can be described as gathering information while viewing and scanning an information space without a specific objective whereas in search there is a specific objective. The two concepts are very similar since both aims at locating required information and there are researchers such as [6] that view browsing and search as an overlapping activity.

Not knowing where they are, not knowing where they can go and not knowing how they can get to a specific place are three problems identified by [7] that can be encountered by users while using a website.

This brings us to an understanding that the challenge of a web designer is to ensure that the process of navigation and search are facilitated in three ways:

- Providing clear and intuitive navigation system to minimize being lost in the web

- Browsing and searching for Information is as effortless as possible

- Promoting the concept of information recognition

The user ability to use the system is another factor that influences the usability of a system i.e. knowing the user is an important point to be considered during the design process. Generally speaking users can be classified for example according to their experience, educational background, age and amount of prior trading.

The user interface design of a system, and more precisely in the context of this research news web pages play a great role in achieving the objective of delivering news to users.

Depending on how usable the news webpage is users can get frustrated from time to time, this happens when a webpage doesn't work properly or when a webpage doesn't provide sufficient information or when users expectation is not met [8]. [9] Claims that if the user discovers that the site contain little useful information or contains a lot of it "bloated graphics" as they call it they go and are unlikely to return.

\section{Navigation}

Finding your way round a webpage is fundamental to the concept of usability and it can only be achieved by having and effective navigation system. [10] States that "navigation is the map and direction of a website" which provide users a tool to get deeper into the website. There are different types of navigation system that are commonly in use for example:

- Hierarchical Navigation Systems is the primary navigation system. However, this type of navigation restricts the user to move within the site just by levels see figure 1 .

- Global Navigation Systems, this type allows users to move within the site freely and complements the information hierarchy.
- Local Navigation Systems, this type is suitable for complex websites and when the site supports sub-sites

- Ad Hoc Navigation, this type of navigation consists of embedded hypertext links of words and phrases within a sentence

\section{Layout}

Layout is considered an important design factor that provides the environment for the content and navigation system of a webpage. Researchers such as [11] insist that for a webpage the layout does not have to be complicated to be useful. One of the layout requirements are the availability of white space, this requirement is based on human reaction to stimulus that can encourage or discourage interest. White color is classed as visually neutral balance for a successful design, whereas composition improves the level of attraction of a webpage

\section{E. Readability}

One of the main aims of webpage creation is information delivery, and the majority of web information is text based, therefore it is important that the readability criterion is considered in webpage designs. Readability is concerned with how easy it is to read and understand a text. Comprehension is a key factor in readability, users should be able to look at and understand lettering of a piece of text.[12] Provides some visual standards that contribute to readability which are:

- Line length, if it is to short it breaks the sentences down and make comprehension difficult, however if the line length is to long it is awkward for eyes.

- Space and contrast, Space in readability is concerned with the space between adjacent works as well as between the lines. The spaces in a text should be adequate for the words to be distinguishable. Contrast is concerned with the color of the text and its background as this plays an important role in the text readability. In general dark colors should write on light colored background and vice versa.

- Alignments, Means which side of the page the text is aligned, to the left, to the right or centered. Mixed alignment in a text should be kept to minimum as it also can impact readability.

\section{F. Colors}

The colors that used in the development of a webpage has direct reflection on the attractiveness the webpage, therefore it is important that the color scheme chosen for a website is based on a scientific ground. In choosing the colors webpage designers have to answer questions such 
as who are the sites potential visitors?, and what is the site's key objective?

On the other hand webpage designers have to be aware of some of the cultural meanings of colors for example red could mean passion, romance, fire, violence, and cowardice depending on the culture. [13] Presents three commonly accepted color schemes (triadic, compound, and analogous) that webpage designers can use.

\section{RELATED RESEARCH}

While some researchers are taking proactive approach by doing research on ideas and steps that should be considered at a HCI design stage others are taking an active approach by evaluating current HCI to identify strength and weakness to improve future designs.[14] is one such research that suggests four lenses for evaluating HCI which are process, invention, relevance and extensibility. For the purpose of this research we have taken a reactive approach by evaluating the webpage interface deigns of news websites in KRI.

Webpage is considered the interface between the internet and people and allow them to exchange information to perform a certain task. For example users input some information into a search engine webpage such as Google to search for a specific information, the task for the website is to find and present the required information.

The quality of web interface design has been researched extensively by [5][15][16][17][18], majority of these studies in their evaluation consider two or three criteria for quality web interface and very few uses multiple criteria. To get a complete view of the quality of the web interface design of a site it is important to take a holistic approach and consider all possible web design criteria and this is what we have implemented in this research.

[19] States that the design of a webpage involves the consideration of human needs on two levels the first one is psychological needs and the second is the sense needs. The sense level involves for example the design of:

- Logical menu

- Area mach

- The logic of the content

- Webpage consistency

- Fonts, colors and images

The psychological level involves the design of:

- Emphasis on the feeling of participation

- Affect the user through multi-sense

- Communicate the information through multidimensions

\section{RESEARCH METHOD}

For the purpose of data collection we used the questionnaire survey method to evaluate 9 most visited news websites in Kurdistan. This was carried out in several stages:

Stage 1: news website selection
We used our knowledge and the internet to create a list of the known news websites active in Kurdistan region. The websites included in the list had to fulfill two criterions:

- Developed and designed by a local company

- Created for news purpose

\section{Stage 2: selecting top visited news websites}

In this stage we feed the web addresses for each of the websites in the list into the Alexa (www.alexa.com) actionable analytical website to identify the 9 top visited websites for the purpose of evaluation. Alexa rates websites by countries and because Kurdistan is a region in Iraq Alexa does not rate websites in Kurdistan region only but all websites contained within Iraq. This means for the purpose of this research a website to be accepted as high rated we have to accept a wider range, therefore we decided to accept news sites rated up to 300 by Alexa

Stage 3: designing the questionnaire

To evaluate the web user interface design of the selected websites we designed a self-completed questionnaire that contained 13 close ended questions that aimed at collecting data regarding 11 web interface design criterions identified by [20] see table 1.The questionnaire was created in the Kurdish language for the obvious reason that our subjects are Kurdish native speakers, this was necessary to ensure that all questions are fully understood by our subjects.

TABLE 1

\begin{tabular}{|l|l|}
\hline No & Criterion \\
\hline 1 & Structure \\
\hline 2 & Usability \\
\hline 3 & Ease of information display \\
\hline 4 & Text style and characteristics \\
\hline 5 & Logo and symbols used \\
\hline 6 & Attraction \\
\hline 7 & Colors \\
\hline 8 & Willingness to read \\
\hline 9 & Promotion of image \\
\hline 10 & Layout \\
\hline 11 & Navigation \\
\hline
\end{tabular}

Stage 4: Sampling

To collect the most accurate result possible we used quota sampling [21] technique and decided that the characteristics of our subject sampling frame target is follows:

- Aged between 18 and 45

- Literate to high school level or above

- Computer literate

- Have interest in news reading

Stage 5: Data collection and recording

The result of each of the 11 criterions recorded in a Microsoft Access database and through a number of different Microsoft Access queries we produced a set of 
results. We then used Microsoft Excel to record result of the queries for later analysis.

Stage 6: Data Analysis

The final stage in the research is to analyze the result for that we calculated the mean for each criteria for all the 9 news websites and produced charts to show the result see figures 3,4 , and 5 .

Because of the availability of the internet and web creation technologies one can assume that there are a lot self-claimed news websites available in KRI some of which can be viewed on (http://www.akurd.net). We decided to choose the news websites rated up to top 300 in Iraq. As a result we identified 9 news websites in KRI that are top rated by Alexa which is one of the most reliable web analytical website available see table 2 for the name of the web sites.

\section{TABLE 2}

\begin{tabular}{|l|l|l|}
\hline No. & News website URL & $\begin{array}{l}\text { Alexa rating for } \\
\text { how popular the } \\
\text { website is in Iraq }\end{array}$ \\
\hline 1 & xandan.org & 7 \\
\hline 2 & basnews.com & 23 \\
\hline 3 & rudaw.net & 25 \\
\hline 4 & knnc.net & 28 \\
\hline 5 & pukmedia.com & 55 \\
\hline 6 & kurdiu.org & 85 \\
\hline 7 & lvinpress.com & 94 \\
\hline 8 & awene.com & 233 \\
\hline 9 & sharpress.net & 246 \\
\hline
\end{tabular}

To collect data for a representative analysis we sent 900 questionnaires to 100 individuals with characteristics stated in step 4 of the research method out of which we received 666 questionnaires back from 74 individuals table 3 is a snapshot of some the results.

TABLE 3

\begin{tabular}{|c|c|c|c|c|c|c|c|c|c|}
\cline { 2 - 11 } \multicolumn{1}{c|}{} & \multicolumn{3}{|c|}{ Structure } & \multicolumn{3}{c|}{ Usability } & \multicolumn{3}{c|}{ Hayperlink } \\
\hline $\begin{array}{c}\text { Name of the } \\
\text { websites }\end{array}$ & Very Good & Good & Not Good & $\begin{array}{c}\text { Very } \\
\text { Difficultt }\end{array}$ & Difficult & Easy & Working Well & $\begin{array}{c}\text { Working } \\
\text { Occasionally }\end{array}$ & $\begin{array}{c}\text { Not } \\
\text { Working }\end{array}$ \\
\hline awene.com & 18 & 45 & 12 & 6 & 33 & 36 & 31 & 37 & 7 \\
\hline basnews.com & 9 & 50 & 10 & 8 & 39 & 22 & 10 & 50 & 9 \\
\hline knnc.net & 29 & 33 & 13 & 7 & 29 & 39 & 29 & 41 & 5 \\
\hline kurdiu.org & 11 & 51 & 7 & 4 & 41 & 24 & 20 & 44 & 5 \\
\hline Ivinpress.com & 12 & 45 & 11 & 7 & 36 & 25 & 25 & 39 & 4 \\
\hline pukmedia & 19 & 37 & 15 & 4 & 34 & 33 & 27 & 35 & 9 \\
\hline rudaw.net & 32 & 36 & 6 & 8 & 21 & 45 & 42 & 27 & 5 \\
\hline sharpress.net & 7 & 55 & 10 & 6 & 45 & 21 & 14 & 53 & 5 \\
\hline xandan.org & 40 & 29 & 5 & 9 & 20 & 45 & 42 & 30 & 2 \\
\hline
\end{tabular}

\section{ANALYSIS AND DISCUSSION}

After the process of data recording we used Microsoft Excel to analyze and produce a number of charts for better visualization and understanding. Through the analyses we wanted to get answers for four main questions:
- What are the percentages of very satisfied, satisfied and not satisfied users generally?

- What is the percentage of very satisfied users per criteria?

- What is the percentage of satisfied users per criteria?

- What is the percentage of not satisfied users per criteria?

To answer the questions we carried out the following calculation before visualizing the answers in a number of charts

$$
\begin{aligned}
1-S C j & =\frac{\sum(C j W 1+C j W 2+\cdots+C j W n)}{n} \text { if } j=c o n s \\
S & =\frac{\sum(S C 1+S C 2+\cdots+S C n)}{n} \\
2-U C j & =\frac{\sum(C j W 1+C j W 2+\cdots+C j W n)}{n} \text { if } j=c o n s \\
U & =\frac{\sum(U C 1+U C 2+\cdots+U C n)}{n} \\
3-V C j & =\frac{\sum(C j W 1+C j W 2+\cdots+C j W n)}{n} \text { if } j=c o n s \\
V & =\frac{\sum(V C 1+V C 2+\cdots+V C n)}{n}
\end{aligned}
$$

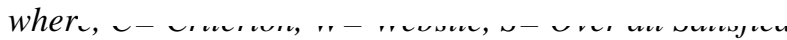
U=unsatisfied, $V=$ Very satisfied

Figure 1 is a graphical representation of the result of question one, which shows the majority of users are satisfied with the design and usability of the news websites. It also shows that the more users are very satisfied than not satisfied see figures 3, 4 and 5 for more details per criterion. This result is probably good news for the web design and development companies working the KRI. However the unsatisfied percentage of users is quite significant and should not be ignored.

\section{Average User Satisfaction}

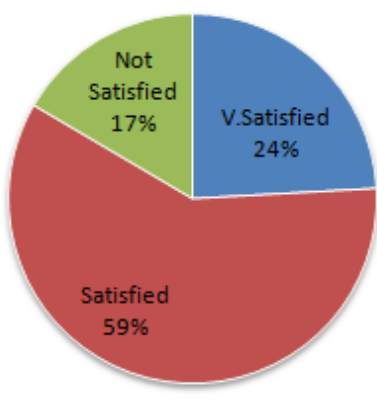

Fig.1 (Over All Result)

To analyze the overall result figure 2 shows the per criteria breakdown for the satisfied users which shows only $36 \%$ of users are satisfied with the functionality of the hyperlinks available in the news web pages. This may be due to the fact that also the WebPages may have been functioning well originally but they lack proper 
administration, which in turn affects the usability of the sites. This claim is supported the result as $44 \%$ of the users are satisfied with the usability aspect of the web pages.

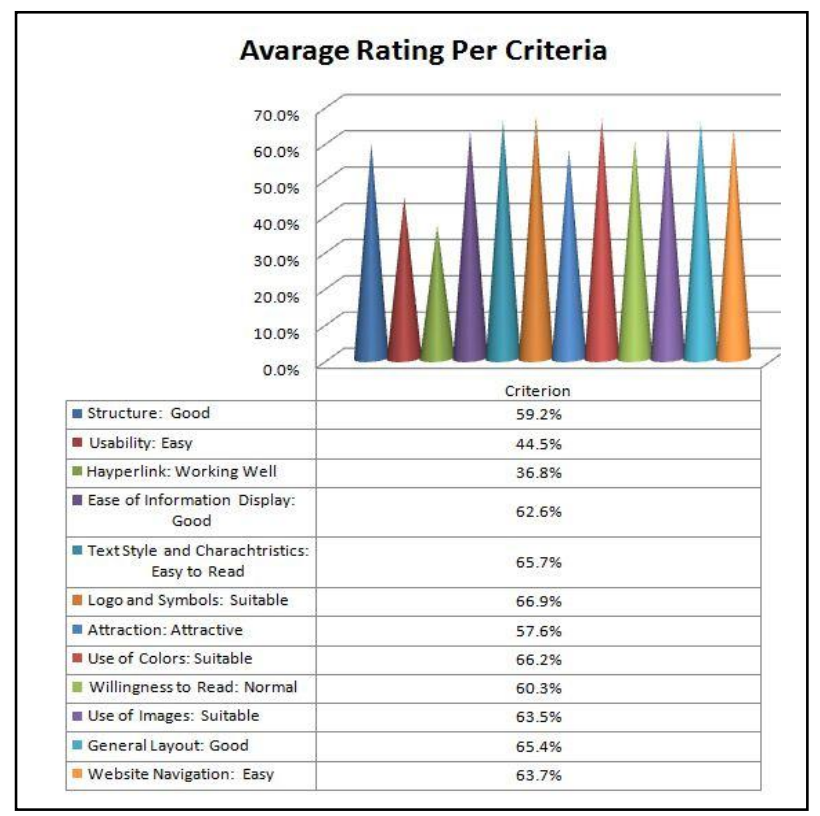

Fig.2 (Average Rating of Criteria)

For a Website to be influential on its users it must be attractive especially in the field of journalism where the majority of the information presented is bad news. Figure 4 show that $26 \%$ of the users believe that the WebPages are not attractive. This we believe is because there are only a few companies working

In the field of web design and development and there is a great demand for new news websites due to the political situation in Iraq. For that reason these companies have turned their priority form quality to quantity.

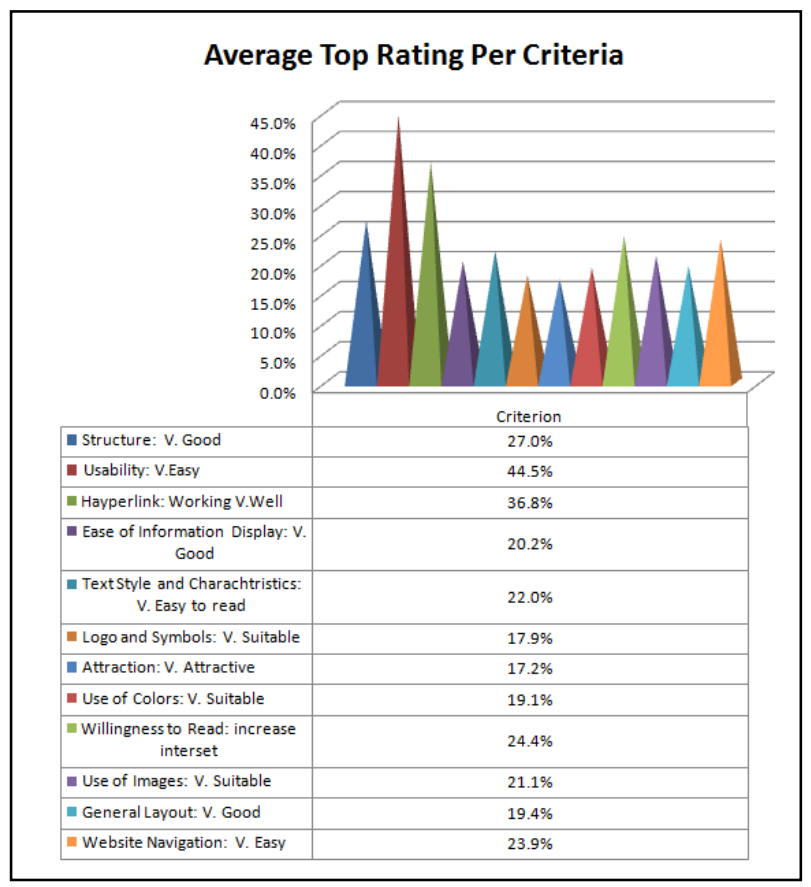

Fig.3 (Average Top Rating Per Criteria)

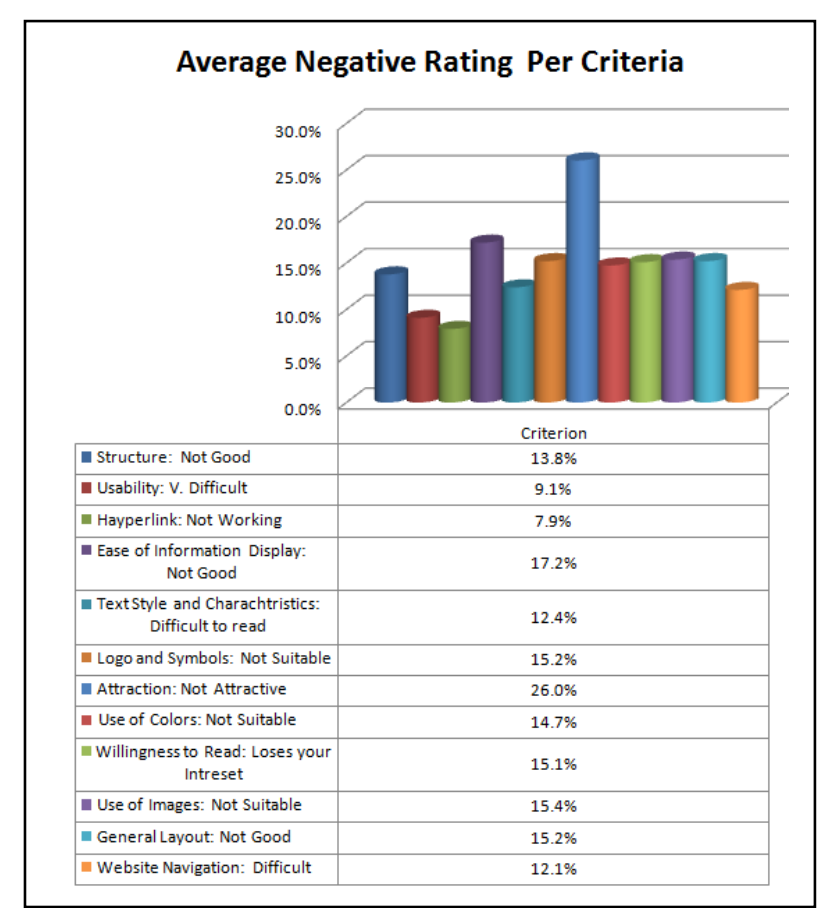

Fig.4 (Average Negative rating Per Criteria)

\section{CONCLUSION}

The use of internet and WebPages to deliver information is relatively new in the KRI; in this paper we have investigated 9 news webpage interfaces that are popular in KRI. We surveyed a population of 100 users and asked questions about 11 WebPages design and usability criterion. Our result show that the $59 \%$ of users are satisfied and $24 \%$ are very satisfied with the quality of design and usability of the web pages but also show that $17 \%$ are not satisfied and there are a number of weaknesses especially in terms of hyperlink functionality and attractiveness that need more attention by designer in KRI.

\section{FUTURE WORK}

We plan to further analyze the data collected in this research to compare the different news websites in order to identify the strength and weaknesses in each. We also have a plan to research the effect of culture on users when making judgments on the websites per criterion.

\section{References}

[1] B. A. Tawfeeq, M. Q. Kheder, and N. N. Qader, "Internet Governance from the Regional Kurdistan of Iraq," Int. J. of Multidisciplinary and Current research, 2014.

[2] "Internet growth and stats," 2000. [Online]. Available: www.internetworldstats.com. [Accessed: 26-01-2015]

[3] T. T. Hewett, R. Baecker, S. Card, T. Carey, J. Gasen, M. Mantei, G. Perlman, G. Strong, and W. Verplank, ACM SIGCHI curricula for human-computer interaction. ACM, 
1992.

[4] F. Karray, M. Alemzadeh, J. A. Saleh, and M. N. Arab, "Human-computer interaction: Overview on state of the art," 2008

[5] W.-S. Fan and M.-C. Tsai, "Factors driving website success-the key role of Internet customisation and the influence of website design quality and Internet marketing strategy," Total Quality Management, vol. 21, no. 11, pp. 1141-1159, 2010.

[6] B. J. Jansen, D. L. Booth, and A. Spink, "Determining the informational, navigational, and transactional intent of Web queries," Information Processing \\& Management, vol. 44, no. 3, pp. 1251-1266, 2008.

[7] F. F.-H. Nah and S. Davis, "HCI research issues in ecommerce," Journal of Electronic Commerce Research, vol. 3 no. 3, pp. 98-113, 2002.

[8] Y. Rogers, H. Sharp, and J. Preece, Interaction design: beyond human-computer interaction. John Wiley $\backslash \&$ Sons, 2011.

[9] G. Sherson, "Website design principles: Researching and building a website evaluation tool," Victoria University of Wellington, Univeral College of Learning submitted to the School of Communications and Information Management. Thesis Master of Communications. Retrieved July, vol. 29, p. 2006, 2002

[10] J. Kalbach, Designing web navigation. " O'Reilly Media, Inc.," 2007

[11] B. Berendt and M. Spiliopoulou, "Analysis of navigation behaviour in web sites integrating multiple information systems," The VLDB Journal-The International Journal on Very Large Data Bases, vol. 9, no. 1, pp. 56-75, 2000.

[12] R. H. Hall and P. Hanna, "The impact of web page textbackground colour combinations on readability, retention, aesthetics and behavioural intention," Behaviour $\backslash \&$ information technology, vol. 23, no. 3, pp. 183-195, 2004.

[13] V. Friedman, "10 Principles of Effective Web Design," Smashing Magazine, vol. 31, 2008.

[14] J. Zimmerman, J. Forlizzi, and S. Evenson, "Research through design as a method for interaction design research in HCI," in Proceedings of the SIGCHI conference on Human factors in computing systems, 2007, pp. 493-502.

[15] T. C.-K. Huang and C.-H. Huang, "An integrated decision model for evaluating educational web sites from the fuzzy subjective and objective perspectives," Computers $\backslash \&$ Education, vol. 55, no. 2, pp. 616-629, 2010.

[16] J. D. Wells, V. Parboteeah, and J. S. Valacich, "Online impulse buying: understanding the interplay between consumer impulsiveness and website quality," Journal of the Association for Information Systems, vol. 12, no. 1, pp. 32-56, 2011.

[17] T. Kaya, "Multi-attribute evaluation of website quality in Ebusiness using an integrated fuzzy AHPTOPSIS methodology," International Journal of Computational Intelligence Systems, vol. 3, no. 3, pp. 301-314, 2010

[18] H. Kim and L. S. Niehm, "The impact of website quality on information quality, value, and loyalty intentions in appare retailing," Journal of Interactive Marketing, vol. 23, no. 3, pp. 221-233, 2009.

[19] G. Xiaodong, "Webpage Human Computer Interface Design," in Multimedia Technology (ICMT), 2010 International
Conference on, 2010, pp. 1-3.

[20] C.-C. Hsu, "Factors affecting webpage's visual interface design and style," Procedia Computer Science, vol. 3, pp. 1315-1320, 2011.

[21] N. Mathers, N. J. Fox, and A. Hunn, Surveys and questionnaires. NHS Executive, Trent, 1998. 